\title{
Design and development of an automatic kilcha (skeining) machine
}

\author{
D. Sargunamani ${ }^{1 *}$, K. Raghu ${ }^{1}$, Subhas V. Naik ${ }^{2}$ \\ ${ }^{1}$ Regional Silk Technological Research Station, Central Silk Technological Research Institute, Central Silk Board, Kancheepuram-631501, INDIA \\ ${ }^{2}$ Central Silk Technological Research Institute, Central Silk Board, Bengaluru-560068, INDIA \\ "Corresponding Author: e-mail: sargunamani@gmail.com, Tel: +(91) 044-27277583 \\ ORCID iD: http:/orcid.org/0000-0002-2652-2945 (Sargunamani), https://orcid.org/0000-0002- 8658- 8663 (Raghu), \\ https://orcid.org/0000-0003-2915-2588 (Naik)
}

\begin{abstract}
Denier test for raw silk testing requires skeins of 450 metres length in slightly twisted form (Kilcha), and the existing process is done manually with skein winder, that has few drawbacks, which are low production, quality and higher time and labour. Hence, the present study proposed to design and develop a machine to rectify the above drawbacks for faster production with good-quality silk skeins, and to reduce testing time and labours involved in work. The innovated machine is designed and developed as automatic skeining (Kilcha) machine and the result showed improvement in production, and quality with reduction in time and labour compared to the manual winder.
\end{abstract}

Keywords: Silk, winding, manual, skein, machine

DOI: http://dx.doi.org/10.4314/ijest.v13i2.3

Cite this article as:

Sargunamani D., Raghu K., Naik S.V. 2021. Design and development of an automatic kilcha (skeining) machine. International Journal of Engineering, Science and Technology, Vol. 13, No. 2, pp. 25-32. doi: 10.4314/ijest.v13i2.3

Received: October 29, 2020; Accepted: October 29, 2020; Final acceptance in revised form: March 19, 2021

\section{Introduction}

Silk is a natural protein fiber, which is composed mainly of fibroin and is produced by insect larvae of mulberry silkworm Bombyxmori to form cocoons, which is best-known silk. Silk is produced by several insects; but, generally, only the silk of moth caterpillars has been used for textile manufacturing (Sutherland et al 2010). There are four types of natural silk which are commercially produced in the world, among them mulberry silk contributes as much as 90 per cent of world production. Other, three types are of non-mulberry silks namely: Eri silk, Tasar silk and Muga silk. There are also other types of non-mulberry silk, which are mostly wild and exploited in Africa and Asia, are Anaphe silk, Fagara silk, Coan silk, Mussel silk and Spider silk (www.worldatlas.com, Gulrajani,1988, Sargunamani and Selvakumar, 2005). India is the second largest producer of silk in the world, about $97 \%$ of the raw mulberry silk produced in six Indian states, namely, Karnataka, Tamil Nadu, Andhra Pradesh, Jammu and Kashmir, Bihar and West Bengal. In Karnataka, North Bangalore, Ramanagara and Mysore, contribute to a majority of silk production. (Deccan Herald 2015, The Hindu, 2008).Post Cocoon Technology of Silk involves silk reeling, Silk throwing, Silk Weaving and Dyeing and Finishing (silk.csb.gov.in, PCT, CSTRI booklets).

Silk reeling is the process by which a number of cocoon baves are reeled together to produce a single thread. This is achieved by unwinding filaments collectively from a group of cooked cocoons at one end in a warm water bath and winding the resultant thread onto a fast moving reel. Raw silk reeling may be classified by direct reeling method on a standard sized reel, indirect method of reeling on small reels, and the transfer of reeled silk from small reels onto standard sized reels on a re-reeling machine. The last technique is primarily applied in modern silk reeling processes. The various silk reeling devices in use are: Sitting Type 
Reeling Machine, Multi-end Reeling Machine and Automatic Reeling Machine (Manual of sericulture, 1987, PCT, CSTRI booklets). Silk can be dyed using direct, reactive, metal complex, colours and various finishes imparted to improve crease, softness etc using various chemicals (Gulrajani,1988; Hojo, 2000; Sargunamani and Selvakumar,2011,2012; Keyworth, 1933).

In silk throwing process, reeled silk skeins are cleaned, twisted and is wound onto bobbins. The yarns (two or more) are twisted together with threads, in a process known as doubling (PCT, CSTRI, booklet). This process makes silk strong enough to be used as organzine for the warp in a loom, or tram for weft (Rayner and Hollins, 1903). Silk throwing was originally a hand process relying on a turning a wheel that twisted four threads while a helper, ran the length of a shade, hooked the threads on stationary pins (the cross)and ran back to start the process again (https://en.wikipedia.org/wiki/Silk_throwing). Presently machines are developed are being used for winding, doubling, twisting (csb.gov.in). Weaving is a method involves two distinct sets of yarns are interlaced at right angles to form a fabric. The longitudinal threads are called the warp the lateral threads are the weft, are inter-woven affects the characteristics of the cloth. There are many types of looms, which are handloom, power loom and shuttle less looms e.g., Rapier type (Collier and Ann, 1974). A handloom weaver works manually to propel the shuttle by throwing it from side to side with the aid of a picking stick. The picking on a power loom is done by rapidly hitting the shuttle from each side using an overpick/underpick mechanism controlled by cams. The rapier-type weaving machines do not have shuttles, they propel the weft by means of small grippers/rapiers that pick up the filling thread and carry it halfway across the loom where another rapier picks it up and pulls it the rest of the way (Talukdar et al., 1998, Sonwalkar and Tammanna, 2001).

Quality assessment of silk involves test method for determining the size of raw silk, deviation, Strength, elongation and winding, calculation method of the results and tolerance for weighing errors are all different from that for the conventional yarns. The standard for testing and classification methods are based on major characteristics which are evenness, cleanness and neatness for grading and price fixation. (Booth , 1996, BIS, IS 15090: 2002, SAC, GB/T 1798-2008 Testing method for raw silk, ISO 2060, ISO 1144). Raw silk is the yarn (filament) reeled from several cocoons, which is continuous from beginning to the end of the skein. The international standard skein should be $148-150 \mathrm{cms}$ in circumference with ribbing not more than $2 \mathrm{~cm}$ at any one of the six ribs. The weight of the skein should be $70-85$ gms up to 24 denier. Denier system is direct management type, employed internationally to measure the size of the thread, which is indicated by the weight of a $450 \mathrm{~m}$ skein in deniers (or $9000 \mathrm{~m}$ weighs 1 $\mathrm{gm}$ is 1 denier). Silk fabrics are produced in a number of varieties, using handlooms and power looms requiring different qualities of raw silk.

Testing of raw silk becomes essential for different grade of reeled silk and the required product is essential for price and quality. Normally, seriplane test and mechanical test are carried out for quality assessment. Linear density test (Denier) involves winding of raw silk at a winding speed of 140 m.p.m followed by reeling on a wrap reel of $1 \mathrm{~m} 12.5 \mathrm{~cm}$ in circumference resulting in a hank of $450 \mathrm{~m}$ in 400 revolutions. After, that hanks are taken wound over manual skein winder to impart slight twist suitable form for weighing them for denier test (manual of sericulture, 1987).Gears are mechanisms that mesh together via teeth and are used to transmit rotary motion from one shaft to another. Gears are mechanisms that are used to transmit rotary motion from one shaft to another and are defined by two important items: radius and number of teeth. They are typically mounted, or connected to other parts, via a shaft or base. Spur Gear is the most common type of gear. Spur gears have teeth that protrude outward from the perimeter of the gear. They are mounted on parallel axes and can be used to create a wide range of gear ratios.

One drawback of this mechanism is that the collisions between each tooth cause a potentially objectionable noise since the entirety of each tooth engages at once. Any two gears that come into contact with one another will naturally produce an equal and opposite force in the other gear. For example, as the one gear engaged with other moves clockwise, the other gear will naturally move counter-clockwise. Any shaft attached to the respective gear will rotate in the direction of the gear it is attached to.(https://www.creativemechanisms.com/gears). The frames of machine tools are made of cast iron or steel. Most of the machine tools for cutting metal are made of cast iron. However, this is not the best material for this purpose in relation to the stiffness obtained from material. Producing steel construction lasts much longer than the treatment of cast iron, Moreover, steel bodies, due to high-quality steel use, are always more expensive than analogous ones made of cast iron. However, they have one indisputable advantage - the size and dimensions of steel details can vary depending on needs, while the performance of casting models for a single detail has no economic justification (https://kimla.pl/en/guide/steel-or-cast-iron).

A belt is a loop of flexible material used to link two or more rotating shafts mechanically, most often parallel. Belts may be used as a source of motion, to transmit power efficiently or to track relative movement. Belts are looped over pulleys and may have a twist between the pulleys, and the shafts need not be parallel (https://en.wikipedia.org/wiki/Belt_(mechanical)-4). Motors are mechanical or electro-mechanical devices that convert energy into motion. Energy, in the form of electrical, hydraulic, or pneumatic, is converted to rotational or linear motion and then output to a shaft or other power transmission component where it provides useful work [https://www.thomasnet.com/articles/machinery-tools-supplies/types-of-motors-5]. The helical spring, in which wire is wrapped in a coil that resembles a screw thread, is probably the most commonly used mechanical spring. It can be designed to carry, pull, or push loads. Twisted helical (torsion) springs are used in engine starters and hinges (https://www.britannica.com/technology/spring-machine-component-6). Machine is a device, tool, apparatus, equipment, or several parts that have been assembled together to do or carry out a particular function or activity. Its main purpose is the make work easier. The advantages are, a) Large scale production: low cost of production, reliable and decreased selling prices and the disadvantages are, job insecurity/jobless, overdependence on machines, sometimes health issues. (https://www.importantindia.com/23805/paragraph-on-advantages-and-disadvantages-of-machines). There are many textile 
machines are available for converting fibre to yarn as spinning machines, weaving machines, dyeing and finishing machines and testing machines (Klein, 2014, Marks and Robinson,1989, Manuals on sericulture 1987, Booth 1996, PCT, CSTRI, booklets), before which manually process were done. Therefore to fulfill the gap in silk testing, to convert manual winding of skeins before denier test to machine winding, this study was undertaken and the innovation of design and development of automatic skeining machine for silk industry testing is the specialty of work and results in terms of production, time and quality have been discussed.

\section{Materials and Methods}

Raw silk supplied by Anna Silk Exchange, Kanchipuram for testing purpose has been used.Materials such as stainless steel, motor, shaft, belt, springs, gears, nut type of fastener with a threaded hole, and bolts procured from local market at Chennai. Prototype machine was manufactured with Local supplier at Chennai. Preliminary trials were undertaken for the adjustment of silk to rotate between the holder and spring on one side of the holder made for front and backward movement. It was planned for 4 skeins to wind at a time with objective to stop the machine for predetermined fixed rotations using electrical counter. The existing process of submission of test reports of raw silk is as follows:

i) Raw Silk Samples (skeins) Collection from Anna Silk Exchange, Kanchipuram

ii) Winding skeins on winding machine for 70 min to find out breaks

iii) Wrap reel to wind 450 metres of length

iv) Silk skeins of 450 metres length are slightly twisted (Kilcha) using manual skein maker

v) Denier test using Auto sorter.

vi) Test reports submission to the customer Anna Silk Exchange, Kanchipuram and in the proposed method the process step remains same as in existing process except that sl.no iv) is replaced with skeins of 450 metres length are slightly twisted using innovated, designed and developed skeining machine.

\section{Results and Discussion}

\subsection{Manual skein winder}

Figure 1 shows the photograph of manual skein winder, presently used for testing purpose. It can be observed that, it has handle to rotate, bevel gears and a hook. The initial form of skein in untwisted form in Figure 2 (a) taken from previous step wrap reel is put into hook by an operator and other end is held in one hand and is rotated using handle and the final form of slightly twisted silk skein (Kilcha) can be seen in Figure 2 (b) for weighing purpose in testing of denier.

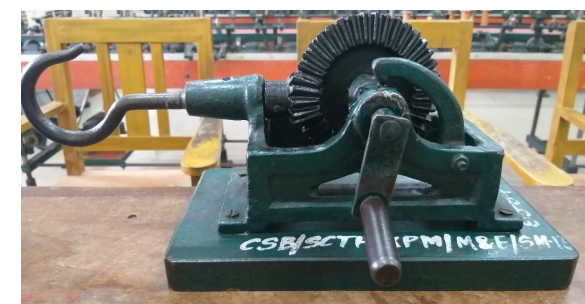

Figure 1. Manual silk skein winder in use for testing purpose

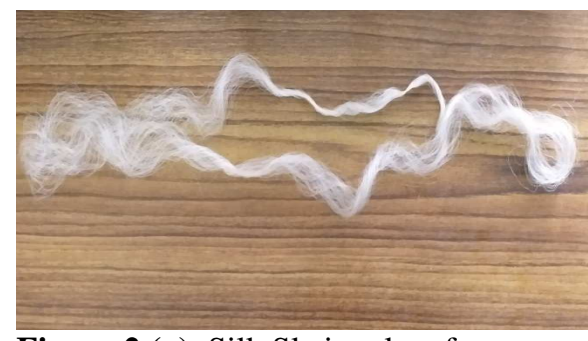

Figure 2 (a). Silk Skein taken from wrap reel initial form (ready for manual

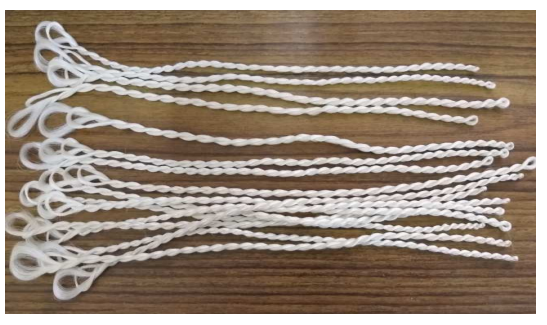

Figure 2 (b). Silk Skein (Kilcha) slightly twisted final form

The advantages of the winder are that, it can be easily operated, very small device, therefore comfortable to work and the disadvantages are for one skein winder, one operator is required, the skein rotation and final product formation depends on operator mood, hygienic is also a concern as well higher time and less production. 


\subsection{Design and Development of skeining machine}

Figure 3 shows the various angle views of the line sketch of the innovated silk skeining (Kilcha) machine to overcome the above drawbacks. Figure 3 (a) shows, $45^{\circ}$ view, the machine consisting of various parts such as stainless steel body, hooks to silk skein, motor, motor pulley, shaft, spur gears. Figure 3 (b) - Top view clearly shows the same parts with belt and pulley and hooks to hold silk. Figure 3 (c) and (d) - Front and side views show motor with pulley and belt and spur gears. The dimensions and motor details of the machine are also shown in Figure 3.

Figure 4(a) to (c) shows various position photographs of the automatic silk skeining (Kilcha) machine, which is designed and developed. It can be seen from the Figures 4(a) and (b) that machine with electrical counter and motor connected to the machine transmits power i.e. electrical energy is converted into mechanical energy through the motor pulley shafts connected with spur gears are rotated and also hooks gets rotated since they are fixed on the same shaft. Intermediate gears placed between corresponding gear hook of $1^{\text {st }}, 2^{\text {nd }}$ and $3^{\text {rd }}$ rotate concerned hooks. The opposite side of the hooks are fixed and fitted with springs for forward and backward movement as shown in Figure 4 (c), since, when silk skein is placed for making slightly twisted silk (Kilcha), the length shrinks, to adjust the movement, these hooks are fitted with springs and it can be observed that, there is no gear connection for this side.

During the preliminary study conducted for the machine problems arised and solutions are discussed here. Initially prototype machine developed based on the concept as shown in Figure 4. After trial experimental studies, few changes have been made for better working of the machine for the issues as follows: a) between the distance of hooks, skeins placed unable to rotate, hence, the concept of length shrink in slight twist of silk brought an idea to use springs for adjustment to move forward and back on one side of the hooks, which has been implemented (Figure 5). b) speed (RPM) of the motor slow has been replaced with higher speed motor (RPM) for faster rotation for optimum condition c) Springs of hooks were harder initially, which is changed for softer movement easier operation. d) Electrical stop motion is attached in which the predetermined no. of revolutions $(0,10,20,30,40$ and so on) can be fixed. e) After, experiments, the results showed that raw silk and twisted silk required 40 revolutions to make silk skein (Kilcha) which is suitable for weighing in required condition Denier test has been found.

\subsection{Method of operating of the skein (Kilcha) machine}

The process steps involved in making Kilcha are as follows:

(a) Loading: Four skeins from wrap reel are loaded

(b) Switch on the machine by fixing 40 revolutions in the electrical counter attached to the machine.

(c) After completion of the 40 revolutions, the required slight twist in skein (Kilcha) is completed, stop the machine unload the skeins and replace with fresh skeins.

(d) Suitable skein (Kilcha) is ready for weighing for denier test.

After experiments, results showed that, implementation in a silk testing unit, better final product of Kilcha (slightly) twisted form is obtained with fixing 40 revolutions in the electrical counter, overall time is reduced by 50 to $60 \%$, labour reduction by 50 to $75 \%$, better quality of silk as handling is reduced, Production increase by 50-60\% and special unique is highly suitable for operators physical health issue in hand. It can be informed that many machines used in manufacturing of textile products, initially it was manually handled and they are developed into suitable machines like charaka winder to pirn winding machine, Charaka reeling to Multiend reeling machines and Automatic reeling machines, manual dyeing to Tub dyeing, ARM dyeing machines. (Manuals on sericulture, 1987, tnsericulture.gov.in, silk.csb.gov.in, https://www.fibre2fashion.com/industryarticle/5740/commercial-silk-dyeing-method-at-varanasi). Various testing machines exist in textile laboratories such as wrap reel, twist tester, winding machines, serigraph (Booth 1996, Manual on Sericulture, 1987). The reason is to increase the production, quality, reduce throughput time and delivery time, customer satisfaction. 

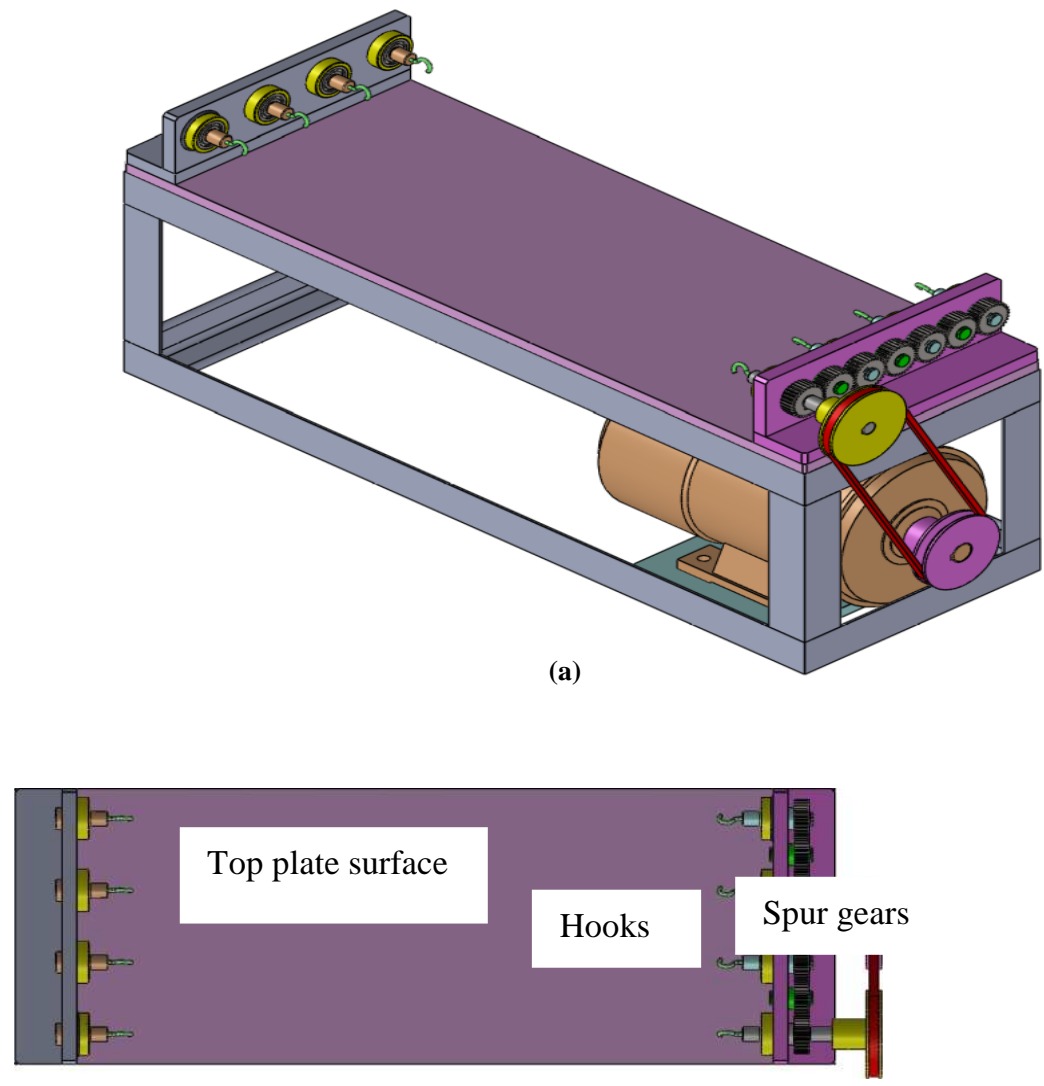

(b)

Pulleys and belt

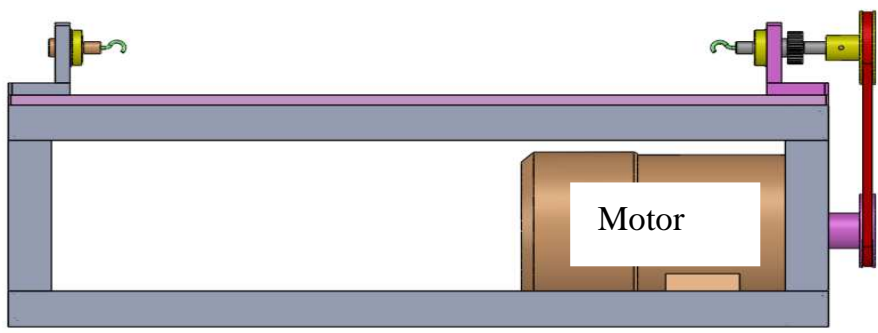

(c)

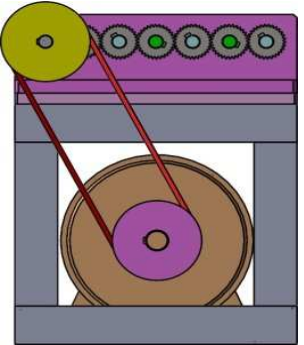

(d)

Dimensions of the machine

Length : $80 \mathrm{cms}$; Motor : HP/kW - 0.16/.12; Width : $35 \mathrm{cms;} \mathrm{RPM} \mathrm{-} \mathrm{1440/92;} \mathrm{Height} \mathrm{:} 31 \mathrm{cms}$; Amp - 0.85;Fixed hook : $9 \mathrm{~cm}$ Variable hook : $25 \mathrm{cms}$

Figure 3. Line Diagram of Automatic Kilcha Machine (a) $45^{\circ}$ View (b) Top view (c) Front View (d) Side view 


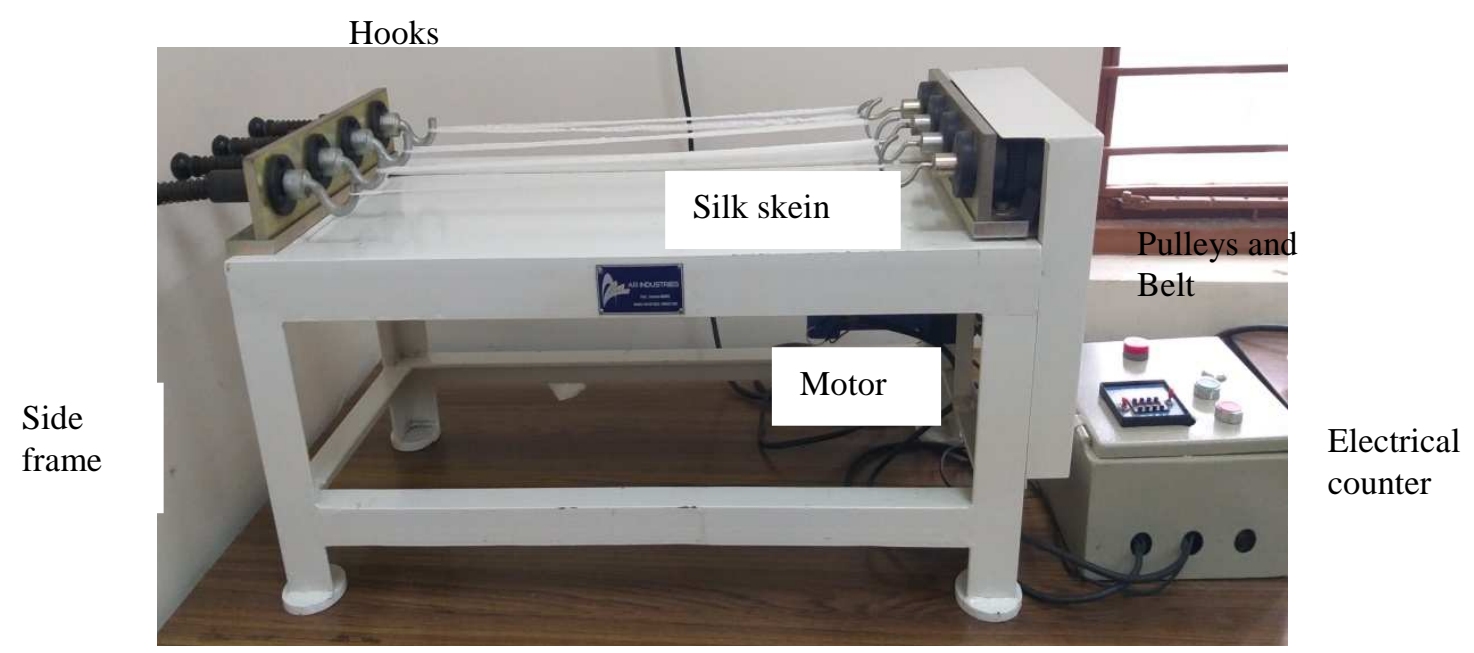

(a)

Forward and backward movement

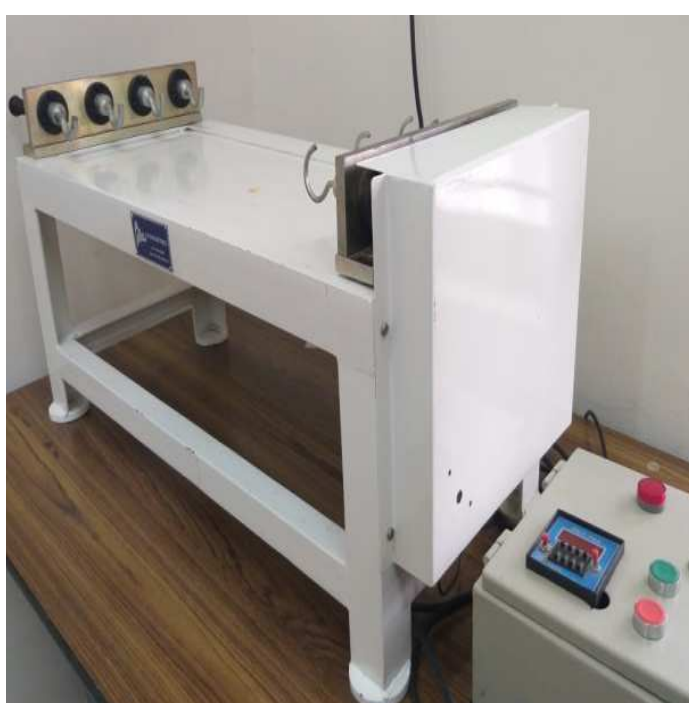

(b)

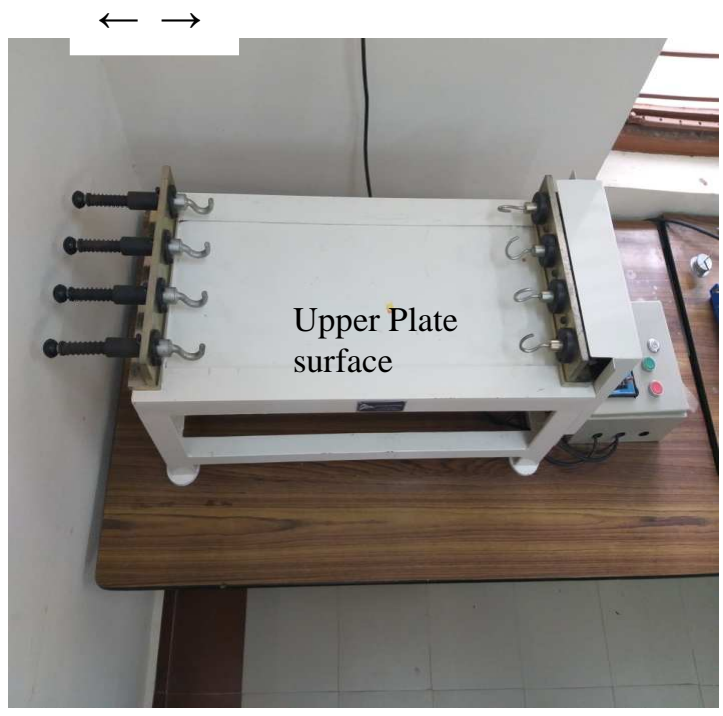

(c)

Figure 4 . Photographs of the designed and developed automatic skeining (Kilcha) Machine (a) Silk Skeins are placed for making Kilcha with electrical counter (b) $45^{\circ}$ View (c) Top view

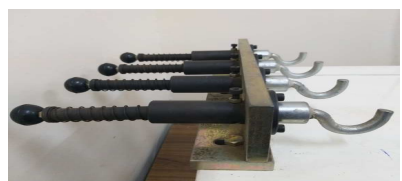

Figure 5 : Photograph of fixed hooks of machine, in which springs fitted assists movement of forward and backward movement to adjust for silk skein length shrinks during the Kilcha making process. 


\section{Conclusion}

The existing manual winder for the production of silk skeins (Kilcha) has drawbacks such as one skein winder requires one operator, the skein rotation and final product depends on operator mood, hygienic is also concern as well as consumes time and production is less. To eliminate the drawbacks, a machine was innovated, designed, and developed as automatic skein (Kilcha) machine that can make skeins (4) at a time. The results showed that, implementation in silk testing unit, overall time is reduced by 50 to $60 \%$, labour reduction by 50 to $75 \%$, better quality of silk as handling is reduced, Production increase by $50-60 \%$ and special unique is highly suitable for operators having physical health issue in hand to rotate and old aged. Further scope, similar kind of machine with fully automatic and higher production of Kilcha making can be designed for industries having multiends and automatic reeling machines for silk, which gives higher production.

\section{References}

Banarjee N.N., 1986. Weaving Mechanism, Textile Book House, 1986

BIS, IS 15090: 2002 Raw silk - Grading and methods of tests

Collier., Ann M., 1974. A Handbook of Textiles, Pergamon Press, p. 258, ISBN 0-08-018057-4

csb.gov.in

Deccan Herald., 2015. Silk city to come up near Bangalore, Archived from the original on 15 July 2015. Retrieved 22 April 2015

Gulrajani M.L., 1988. Silk Dyeing, Printing, and Finishing, Department of Textile Technology, Indian Institute of Technology, New Delhi, India

Hojo N., 2000. Structure of Silk Yarn Part B: Chemical structure and processing of silk yarn, Science Publishers, England

https://en.wikipedia.org/wiki/Belt_(mechanical)

https://en.wikipedia.org/wiki/Silk_throwing\#CITEREFRayner1903)

https://kimla.pl/en/guide/steel-or-cast-iron3

https://www.britannica.com/technology/spring-machine-component

https://www.creativemechanisms.com/gears

https://www.fibre2fashion.com/industry-article/5740/commercial-silk-dyeing-

https://www.importantindia.com/23805/paragraph-on-advantages-and-disadvantages-

https://www.thomasnet.com/articles/machinery-tools-supplies/types-of-motors.

ISO 1144, Textiles. Universal system for designating linear density (Tex System)

ISO 2060, Textiles. Yarn from packages. Determination of linear density (mass

Keyworth C. M., 1933. Silk Dyeing. Journal of the Society of Dyers and Colourists, First published: August 1933.https://doi.org/10.1111/j.1478-408.1933.tb01765.x

Klein W., 2014.The Rieter Manual of Spinning, Vol.1-3, Rieter Machine Works Ltd., Winterthur

Maff of Japan, 1996. Silk test specification and rules

Marks R., and Robinson. T.C., 1989. Principles of Weaving, The Textile Institute, Manchester

Manual on sericulture. 1987. Silk Reeling, by Central Silk Board, Bangalore, India.

Post Cocoon Technology (PCT).Central Silk Technological Research Institute (CSTRI) Booklets, Central Silk Board, Bengaluru, India

Rayner., Hollins., 1903. Silk throwing and waste silk spinning. Scott, Greenwood, Van Nostrand. OL 7174062M

SAC, GB/T 1798-2008 Testing method for raw silk

Sargunamani D., 2005. A study on the effect of ozone treatment on the properties of mulberry and tassar silk fabrics, Ph.D thesis, Anna University, Chennai, India.

Sargunamani D.,Selvakumar N., 2012. Effects of ozone treatment on the dyeing properties of mulberry and tassar silk fabrics, Journal of Engineered fibres and fabrics, Vol.7, No. 3, pp. 21-27.

Sargunamani D., 2011. Commercial method of dyeing silk at Varanasi. https://www.fibre2fashion.com/industryarticle/5740/commercial-silk-dyeing-method-at-varanasi.

silk.csb.gov.in

Sonwalkar T.N., 2001. Handbook of Silk Technology, New Age International (P) Ltd., New Delhi, India

Sutherland T.D., Young J.H., Weisman S., Hayashi CY., Merritt D.J., 2010. Insect silk: one name, many materials. Annual Review of Entomology. 55: 171-88. doi:10.1146/annurev-ento-112408-085401. PMID 19728833

Talukdar M.K., Sriramulu P.K., Ajgaonkar D.B., 1998. Machines, Mechanisms, Management; Mahajan Publishers, India

The Hindu, 2013. Tamil Nadu's first automatic silk reeling unit opened, 24 August 2008. Archived from the original on 19 October 2013. Retrieved 9, November 2013

tnsericulture.gov.in 


\section{Biographical notes}

D. Sargunamani is working as Scientist D, at Regional Silk Technological Research Station (RSTRS), Kanchipuram, which is a subunit of Central Silk Technological Research Institute (CSTRI) under Central Silk Board, Bengaluru, India. He has vast experience in teaching, Industry and research.He has published more than 20 papers in national/International journal in textile research topics and in silk technology related topics. He has also presented/published research articles in national and international conferences.

K. Raghu received his M.Tech degree from PSG college of Technology, Coimbatore and M.Phil degree from SK university. Presently working as Scientist with Central Silk Board having more 30 years experience. He has published and presented many papers in National/International journal and in Conferences.

Subhas V. Naik is Director at Central Silk Technological Research Institute (CSTRI) under Central Silk Board, Bengaluru, India. He has vast experience in teaching, Industry and research in post cocoon technology of silk. He has published more than 80 papers in national/International journals with 4 publications of books in silk research topics. He has also presented more than 50 research articles in national and international conferences. 